\title{
A new continuous-flow solar water disinfection system inactivating cysts of Acanthamoeba castellanii, and bacteria
}

\author{
Beni Jequicene Mussengue Chaúque ${ }^{1,3}\left[\right.$. Antônio Domingues Benetti ${ }^{2} \cdot$ Gertrudes Corção $^{1} \cdot$ Carlos Eugênio Silva $^{1}$. \\ Rodrigo Fernandes Gonçalves ${ }^{1} \cdot$ Marilise B. Rott ${ }^{1}$
}

Received: 15 December 2020 / Accepted: 16 December 2020 / Published online: 25 January 2021

(c) The Author(s), under exclusive licence to European Photochemistry Association,European Society for Photobiology 2021

\begin{abstract}
Solar water disinfection (SODIS) is an effective and inexpensive microbiological water treatment technique, applicable to communities lacking access to safely managed drinking water services, however, the lower volume of treated water per day $(<2.5 \mathrm{~L}$ per batch) is a limitation for the conventional SODIS process. To overcome this limitation, a continuous-flow solar water disinfection system was developed and tested for inactivation of Acanthamoeba castellanii cysts and Escherichia coli, Salmonella Typhimurium, Enterococcus faecalis, and Pseudomonas aeruginosa. The system consisted of a solar heater composed of a cylindrical-parabolic concentrator and a UV irradiator formed by a fresnel-type flat concentrator combined with a cylindrical-parabolic concentrator. Deionized water with low or high turbidity $(<1$ or 50 nephelometric turbidity unit (NTU) where previously contaminated by $10^{8} \mathrm{Cysts} / \mathrm{L}$ or $10^{5}-10^{6} \mathrm{CFU} / \mathrm{mL}$ of each of four bacterial species. Then was pumped from the heating tank flowing through the heater and through the UV irradiator, then returning to the heating tank, until reaching $45,55,60$ or $70{ }^{\circ} \mathrm{C}$. The water was kept at the desired temperature, flowing through the UV irradiator for 0.5 and $10 \mathrm{~min}$. Trophozoites were not recovered from cysts (during 20 days of incubation) when water with $<1$ NTU was exposed to UV and $60{ }^{\circ} \mathrm{C}$ for $0.5 \mathrm{~min}$. In water with $50 \mathrm{NTU}$, the same result was obtained after $10 \mathrm{~min}$. In water with $<1$ NTU, the inactivation of all bacteria was achieved when the water with $<1 \mathrm{NTU}$ was exposed to $55^{\circ} \mathrm{C}$ and UV for $0.5 \mathrm{~min}$; in water, with $50 \mathrm{NTU}$ the same result was achieved by exposure to $60{ }^{\circ} \mathrm{C}$ and UV for $0.5 \mathrm{~min}$. The prototype processes $1 \mathrm{~L}$ of water every $90 \mathrm{~s}$. The system is effective and has the potential to be applied as an alternative to the large-scale public drinking water supply.
\end{abstract}

Marilise B. Rott

marilise.rott@ufrgs.br

1 Department of Microbiology, Immunology and Parasitology,

Institute of Basic Health Sciences, Universidade Federal

Do Rio Grande Do Sul, Sarmento Leite Street, N 500,

Porto Alegre, Rio Grande do Sul 90050-170, Brazil

2 Department of Hydraulic Works, Hydraulic Research Institute, Universidade Federal Do Rio Grande Do Sul, Bento Gonçalves street 9500, Porto Alegre, Brazil

3 Department of Natural Sciences, Mathematics and Statistics, Niassa Branch, Universidade Rovuma, Nangala campus, Lichinga City, Mozambique 


\section{Graphic abstract}

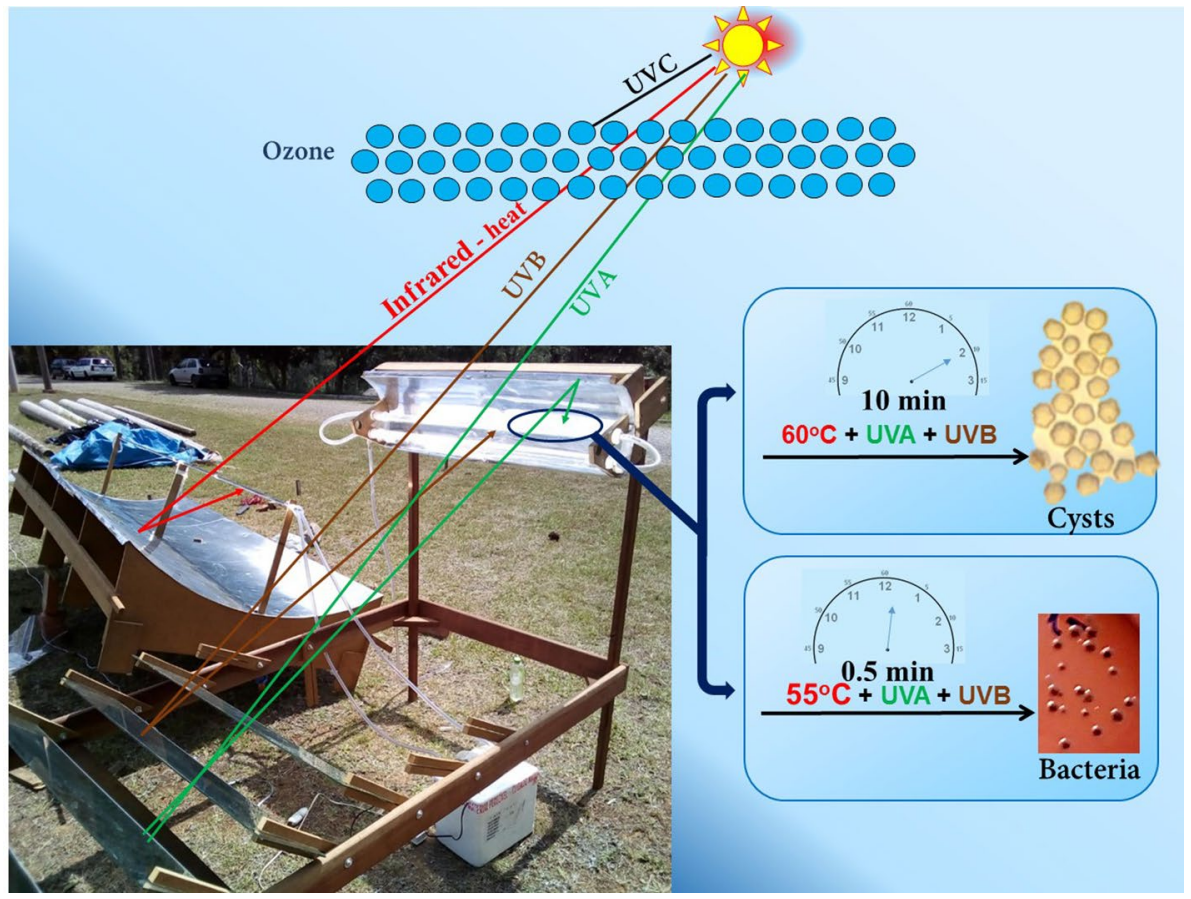

\section{Introduction}

Solar disinfection (SODIS) has attracted interest from several groups, especially in the last $2-3$ decades, which have demonstrated its effectiveness in the microbiological treatment of water [1-3]. SODIS has been shown to be an inexpensive technique for microbiological water treatment that has an expressive cost-benefit advantage $[2,4]$ and is capable to increase safe water access and reducing the occurrence of waterborne diseases, especially in regions of the planet that receive abundant solar radiation. The highest prevalence of waterborne diseases is reported from developing countries that receive abundant solar radiation, where, coincidentally, the majority of the population lacking access to drinking water services is concentrated $[1,2,5]$.

Solar disinfection occurs by the synergic effect of heat and/or UV radiation, when it induces irreversible cell damage (such as enzyme inactivation, damage to organelles and genome) to microorganisms present in water exposed to the sun [6-8]. In several studies using SODIS or solar pasteurization (SOPAS), inactivation or a reduction in viability of various microorganisms (such as bacteria, helminth eggs, viruses, fungi and protozoan cysts and oocysts) has been achieved using batch approaches $[1,3,9]$. However, the amount of water treated by conventional SODIS process is dependent upon to the availability of transparent containers, usually polyethylene terephthalate (PET) bottles, as they are inexpensive [1]. To overcome this problem, some groups have been developing continuous or semi-continuous solar water disinfection systems based on solar collectors, which are mostly concentrator types [10-14]. In general, continuous-flow solar water disinfection systems are designed to expose contaminated water to the effect of sufficiently high doses of solar thermal energy or solar UV radiation to inactivate microorganisms during the short exposure time.

Inactivation of Escherichia coli has been achieved by some continuous-flow solar water disinfection [10, 14]. These authors used $E$. coli to evaluate the effectiveness of their prototypes, however, despite as an indicator of microbiological water quality, it is relatively more sensitive than many water-borne microorganisms such as some protozoa, fungi, and viruses, as reported by various groups, for example [1,3]. Achieving the effectiveness of continuous water disinfection is a decisive step for SODIS to be applicable to large-scale public water supply as it solves the problem of the small volume of treated water per day. However, for SODIS in a continuous flow to be considered safe, it must be able to inactivate, in addition to bacteria, other resistant microorganisms, such as Acanthamoeba spp. cysts.

The WHO Guidelines for drinking water quality consider that quantifying the microbiological risk of drinking water to public health is attributed to one hazard at a time; 
however, monitoring an indicator such as Escherichia coli is recommended because it is more economically viable. Although the absence of $E$. coli does not necessarily indicate the absence of other bacteria, the treated drinking water must contain $0 \mathrm{CFU} / 100 \mathrm{~mL}$ of this indicator. Although the WHO drinking-water guidelines consider Acanthamoeba spp. as a waterborne pathogen associated with outbreaks of diseases of high incidence and severity, and of high persistence, resistance and infectivity, it does not establish minimum tolerable values in drinking water, as it presents a low risk to gastrointestinal health if ingested [38]. On the other hand, Cryptosporidium parvum and Giardia spp. are in the WHO's guidelines for drinking water and their monitoring is recommended, but they are more difficult to monitor than Acanthamoeba spp., which is also a protozoan with very resistant cysts, and perhaps as much or more resistant than oocysts of $C$. parvum and cyst of Giardia spp. Acanthamoeba spp. can be used as an adequate indicator of the presence of protozoa in drinking water, as in addition to being one of the most resistant microorganisms to disinfection, being able to host and disperse a wide range of pathogenic bacteria in drinking water, they are highly prevalent and easy to monitor [15, 38, 39].

Acanthamoeba spp. cysts have been shown to be resistant to extreme physical and chemical conditions, such as $\mathrm{pH} 2.0$, freezing, gamma radiation ( $250 \mathrm{rads})$, UV radiation $(800 \mathrm{~mJ} /$ $\mathrm{cm}^{2}$ ), moist heat, desiccation for more than 20 years, and chlorine [5, 15-17]. The genus Acanthamoeba is of great clinical, environmental and sanitary importance, in addition to being amphizoic, and can harbour and carry various types of viruses and pathogenic bacteria, spreading them in various environmental matrices, including chlorinated water from the public network $[15,18]$. Within amoebae, microorganisms can recombine their genes, resulting in the acquisition or increase of virulence [19].

Most of the continuous-flow solar water disinfection systems described in the literature are designed to use essentially thermal energy (SOPAS) or solar UVA and B [2, $10-14,20]$. To enable the inactivation of resistant microorganisms, we designed and built a continuous-flow solar water disinfection system, capable of using the synergistic effect of solar heat and UV radiation. The system built consisted of a solar heater comprising of a cylindrical-parabolic concentrator and a UV irradiator consisting of a Fresnel type concentrator combined with a cylindrical-parabolic concentrator [21]. Its effectiveness was evaluated for disinfection of water previously contaminated with cysts of Acanthamoeba castellanii and cells of Escherichia coli, Salmonella Typhimurium, Enterococcus faecalis, and Pseudomonas aeruginosa. The system was able to inactivate the cysts and all bacteria species tested. As expected, bacteria were more sensitive than cysts to the effect of heat and, especially, to the synergistic effect of heat and UV radiation.

\section{Materials and methods}

\subsection{Photometry of the optical materials for the system}

Samples of aluminium-metallized polyester-adhesive, stainless steel and common glass mirror were evaluated for their reflectance to infrared (IR), UVA and UVB radiation. Similarly, wall samples from two quartz tubes with different purity levels were evaluated for their UVA and UVB transmittance. Reflectance and transmittance measurements were performed using the Cary 5000 spectrophotometer, version 2.24 , according to the manufacturer's guidelines. The aluminium-metallized polyester-adhesive was selected as the reflective material for use in the construction of the heater and the UV irradiator because it had a high reflectance for infrared (79.2\%) and UV (74.7\%) spectrum and because it is cheaper, easily available and easy to use.

\subsection{System construction}

The system prototype consisted of a heater and a UV irradiator, and its structure was made of wood. The heater consisted of a parabolic cylindrical solar concentrator measuring $3.0 \mathrm{~m}$ long and $1.173 \mathrm{~m}$ wide. The heater design was performed as previously described [22], using an aperture angle of $70^{\circ}$, because it is an angle with greater concentration [23]. An absorber consisting of two parallel aluminum tubes measuring $1.0 \mathrm{~cm}$ in diameter was placed in the focus line of the concentrator (Fig. 1). The tubes were painted matte black to absorb the solar infrared (IR) energy concentrated upon them by the concentrator and to turn it into internal heat [24].

The UVA and UVB irradiator consisted of a combination of linear fresnel primary concentrator [12] and a parabolic cylindrical secondary concentrator. The primary concentrator had 25 mirrors measuring $1.0 \mathrm{~m} \times 20 \mathrm{~cm}$ fixed on a horizontal support, occupying an area of $4.5 \mathrm{~m} \mathrm{[2].}$ The surface of the mirrors was coated with an aluminiummetallized polyester adhesive (Fig. 1).

The secondary concentrator measuring $1.0 \mathrm{~m}$ long and $0.27 \mathrm{~m}$ wide was placed at the end of the horizontal mirror support (primary concentrator). The design of the two parabolas (heater and the secondary concentrator) was carried out as previously described [22], using an aperture angle of $70^{\circ} 0.23$ The surface of the parabolas was coated with an aluminium-metallized polyester-adhesive. The focus was determined visually by identifying the intersecting line of the light beams.

In the focus line of the secondary concentrator, a quartz tubular reactor (reactor 3 ) of $2.5 \mathrm{~cm}$ in diameter 


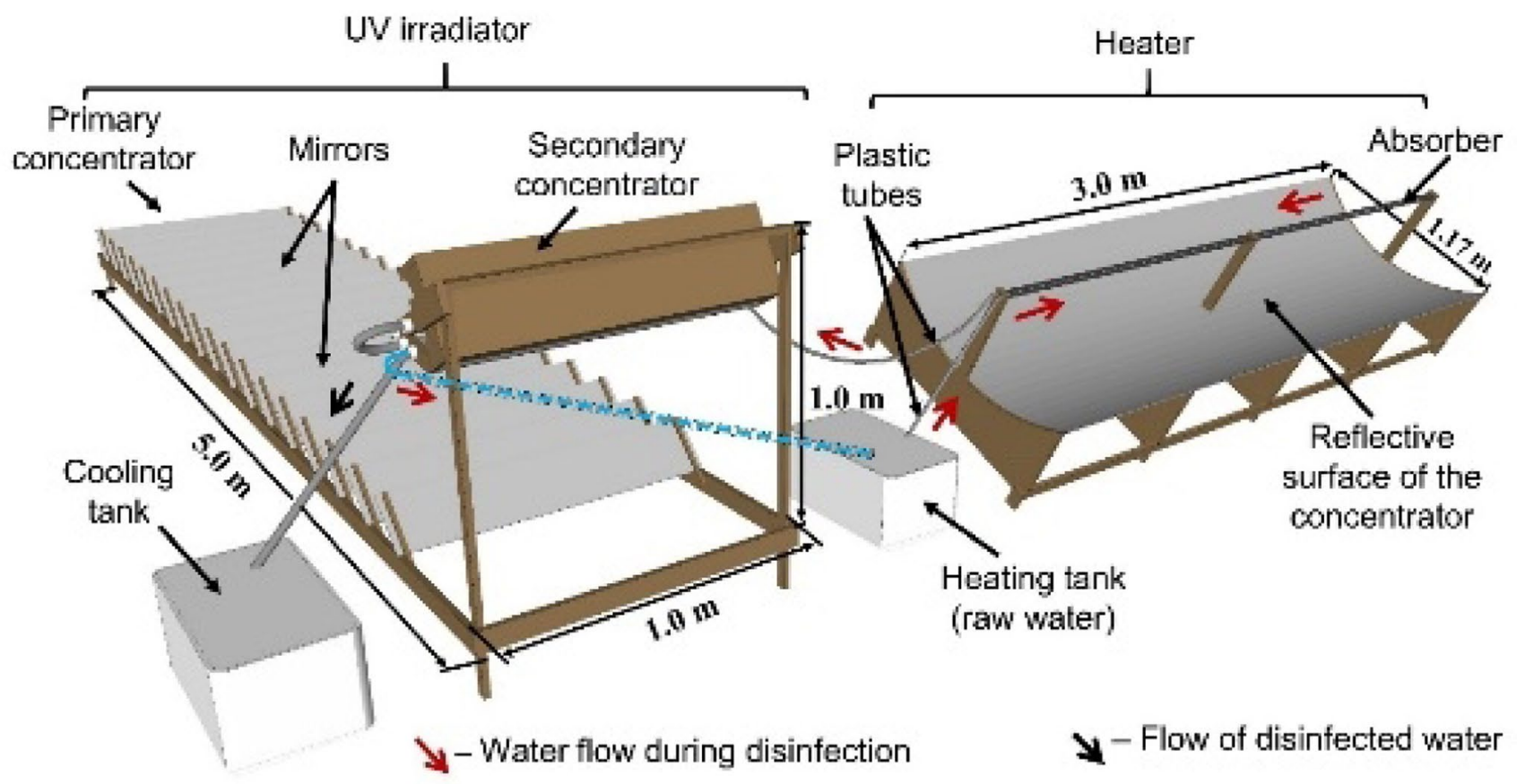

Fig. 1 Design overview of the continuous-flow solar water disinfection system, showing the disposition of its different constituents. During treatment, water flows from the heating tank to the heater and then to the UV irradiator, returning to the heating tank. When the

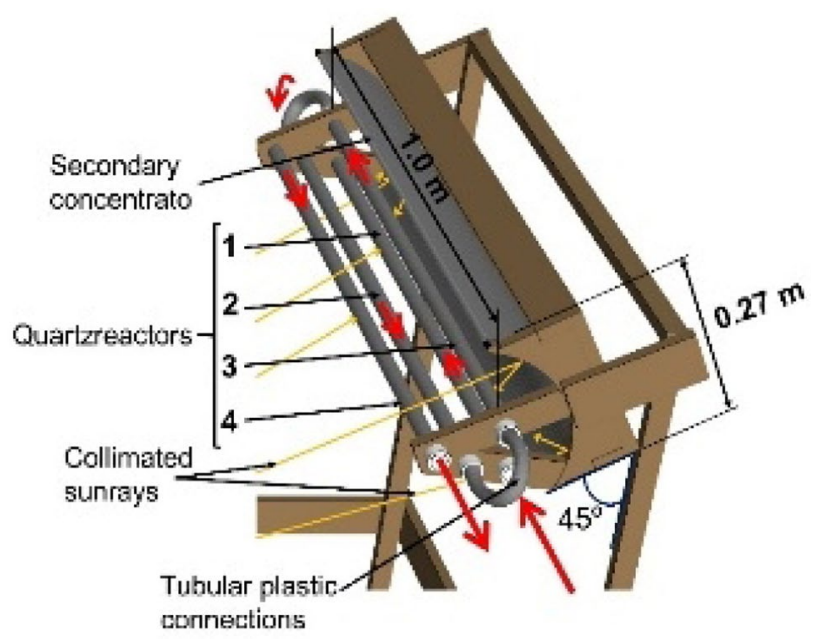

Fig. 2 Details of the secondary concentrator of the UV irradiator. Red arrows show the flow inlet, flow direction and water outlet

was placed. Parallel to this, two more tubular reactors (reactor 1 and 2) were placed. The secondary concentrator was placed in the focus of the primary concentrator (Fig. 2). It is desirable that the secondary concentrator has the largest possible number of quartz reactors, as this increases the time the water remains in the UV irradiator conditions for complete disinfection are established, the reflux cycle of the water is interrupted, and the water is directed to the cooling tank

and consequently increases the exposure time to UV. The designed secondary concentrator allows the use of up to four reactors; however, one of the reactors was defective; therefore, all tests and estimates presented were carried out with three reactors. Additional details on the construction of the system are described in patent registration number BR02020001683-0A2.

\subsection{System operation}

Untreated contaminated water was introduced into the heating tank. The tank was made of Styrofoam and had a capacity of $10 \mathrm{~L}$. During the tests, a $13 \mathrm{~W}$ submerged pump was used, adjusted to a flow rate of $500 \mathrm{~L} / \mathrm{h}$. The pump flow value was determined by measuring the amount of water that leaves the UV irradiator per minute. Water flowed through plastic tubes to the heater, running $6 \mathrm{~m}$ long from the absorber, warming up, then flowing to the UV irradiator. In the UV irradiator, water flows through the quartz tubular reactors, running through reactors 1,2 and 3, being irradiated by UVA and UVB radiation. When water came out of the UV irradiator it flowed back into the heating tank or cooling tank, depending on the treatment being implemented, or the treatment step (Fig. 1). 


\subsection{Obtaining solarimetric data}

The experiments were carried out in the summer of the state of Rio Grande do Sul, in the city of Porto Alegre, in the months of January, February and March 2019, starting at 10 a.m.

Insolation data were obtained from the National Institute of Meteorology (INMET) website (http://www. inmet.gov.br/portal/). The data were measured at Station 86,988, located in the city of Porto Alegre, located at latitude -30.05 , longitude -51.16 at an elevation of $46.97 \mathrm{~m}$. INMET is an agency of the Brazilian Ministry of Agriculture, Livestock and Supply, and has a network of modern automatic weather stations that collect data that is published in real-time.

The ultraviolet radiation index data were obtained from the Weather Forecast and Climate Studies Center (CPTEC) website of the National Institute for Space Research (INPE) (http://satelite.cptec.inpe.br/uv/). The data were measured at Station 83971, located in Porto Alegre, located at latitude -29.99 , longitude -51.17 at an altitude of $3 \mathrm{~m}$. The UV index value was converted to the equivalent value in energy, multiplying by 25 , which is the corresponding energy value of each index unit [25]. The stations were $6.5 \mathrm{~km}$ from the experiment site.

\subsection{Estimation of UV radiation inside reactors}

Ultraviolet radiation was not measured directly inside the quartz tubular reactors; it was estimated using Eqs. 1 and 2. Total UV irradiance within the reactor $\left(I_{\mathrm{UVr}}\right)$ includes UVA and UVB irradiance. The intensity of UV irradiance inside reactors 1 or $2\left(I_{\mathrm{UVr} 1}\right.$ or $\left.I_{\mathrm{UVr} 2}\right)$ was less than the irradiance inside reactor $3\left(I_{\mathrm{UVr} 3}\right),\left(I_{\mathrm{UV} 1}\right.$ or $\left.2<I_{\mathrm{UVr} 3}\right)$. This is because reactors 1 and 2 are placed only in the focus of the primary concentrator, while reactor 3 is placed also in the focus of the secondary concentrator. The $I_{U V r} 1$ or 2 was estimated from Eq. 1

$I_{\mathrm{UVr}} 1$ or $2=\left(D_{\mathrm{UVI}} \cdot A_{\mathrm{CS}} \cdot R_{\mathrm{PC}}\right) \frac{1}{8} \cdot T_{\mathrm{r}}$

where $D_{\mathrm{UVI}}$ is the direct ultraviolet irradiation, measured at the time of the experiment. $A_{\mathrm{SC}}$ is the concentration surface area, which corresponds to the area occupied by the irradiator primary concentrator mirrors, which was $4.5 \mathrm{~m}^{2} . R_{\mathrm{PC}}$ is the reflectance of the primary concentrator, corresponds to the reflectance of aluminium-metallized polyester adhesive. The average reflectance of the adhesive for the UVA and UVB spectra was considered. The reflectance for UVA was determined by calculating the arithmetic mean of the reflectance including each point from the upper to the lower limit of the spectral range (315-400 $\mathrm{nm})$. The same procedure was applied for UVB, considering the spectral range of $280 \mathrm{~nm}$ and $315 \mathrm{~nm} . T_{\mathrm{r}}$ is the transmittance of the quartz tube wall. The mean transmittance for the UVA and UVB range was considered, using the same procedures previously described for reflectance. The divider value (1/8) corresponds to the area occupied by the reactor within the focus line thickness $(0.20 \mathrm{~m})$ of the primary concentrator. It is the product of the thickness of the primary concentrator focus line by the diameter of the quartz reactor $(0.025 \mathrm{~m})$.

The $I_{\mathrm{UVr} 3}$ was estimated from Eq. 2.

$I_{\mathrm{UVr} 3}=\left[\left(D_{\mathrm{UVI}} \cdot A_{\mathrm{SC}} \cdot R_{\mathrm{PC}}\right) R_{\mathrm{SC}}\right] T_{\mathrm{r}}+I_{\mathrm{UVr}} 1$ or 2

where $R_{\mathrm{SC}}$ is the reflectance of the secondary concentrator, corresponds to the reflectance of the aluminium-metallized polyester-adhesive, used to coat the surface of the secondary concentrator parable. The mean reflectance of UVA and UVB was considered as previously described in Eq. 1. The estimates of the radiological conditions during the experiments are presented in Table 1.

\subsection{Water preparation}

Deionized water by reverse osmosis was used. In the experiments, low turbidity water $(<1 \mathrm{NTU})$ and high turbid water (50 NTU) were tested. The 50 NTU turbidity has been defined as it is above the maximum recommended value for the conventional SODIS process since the literature reports that water turbidity levels above 30 NTU compromise the efficiency of SODIS [26, 27]. High turbid water was obtained by suspending kaolin in water. Kaolin was added gradually with a vigorous stirring of the hermetically sealed container, followed by turbidity measurement using a $\mathrm{HACH}$ 2100 turbidimeter. The water was sterilized by autoclaving at $121^{\circ} \mathrm{C}$ for $15 \mathrm{~min}$ before use.

\subsection{Preparation of Acanthamoeba castellanii cysts stock}

Cysts of environmental Acanthamoeba castellanii, Neff strain, ATCC 30010 were used. The axenic culture of $A$. castellanii trophozoites was carried out in cell culture bottles containing PYG medium (2\% peptone proteose, $0.2 \%$ yeast extract and $1.8 \%$ glucose) at $30{ }^{\circ} \mathrm{C}$ for 5 days. After this period, the medium was discarded, and the bottles were gently washed twice with Neff's encystment solution $(0.1 \mathrm{M}$ $\mathrm{KCl}, 0.02 \mathrm{M}$ Trisamine, $8 \mathrm{mM} \mathrm{MgSO}{ }_{4}, 0.4 \mathrm{mM}, \mathrm{CaCl}_{2}$, $1 \mathrm{mM} \mathrm{NaHCO} 3$ ). Cells were maintained for seven days in the $10 \mathrm{~mL}$ of Neff's encystment solution supplemented with $100 \mu \mathrm{L}$ of antibiotics (in a 1: 1 ratio of Potassic Penicillin G and Streptomycin). The cysts were then harvested by centrifugation (2800 rpm for $5 \mathrm{~min}$ ), the supernatant was discarded, 
Table 1 Characterization of the radiological conditions of the experiment

\begin{tabular}{|c|c|c|c|c|c|c|c|c|}
\hline Target & Treatment & NTU & Date & $\mathrm{T}^{\circ} \mathrm{C}$ & $\begin{array}{l}\text { Insola- } \\
\text { tiona }(\mathrm{kJ} / \\
\left.\mathrm{m}^{2}\right)\end{array}$ & $D_{\mathrm{UVI}}\left(\mathrm{mW} / \mathrm{m}^{2}\right)$ & $\begin{array}{l}I_{\mathrm{UVr} 1 \text { or } 2} \\
\left(\mathrm{~mW} / \mathrm{m}^{2}\right)\end{array}$ & $I_{\mathrm{UVr} 3}\left(\mathrm{~mW} / \mathrm{m}^{2}\right)$ \\
\hline \multirow[t]{4}{*}{ Cysts } & \multirow[t]{2}{*}{ Heat + UV } & $<1$ & $06 / 02 / 19$ & 24 & 1471 & 225 & 80.6 & 562.2 \\
\hline & & $<1$ & $07 / 03 / 19$ & 26 & 263 & 175 & 62.7 & 437.3 \\
\hline & Heat + UV & 50 & 26/03/19 & 19 & 230 & 150 & 53.7 & 374.8 \\
\hline & Heat & $<1$ & $14 / 03 / 19$ & 23 & 355 & 200 & 71.6 & 499.7 \\
\hline \multirow[t]{8}{*}{ Bacteria } & \multirow[t]{3}{*}{ Heat $\rightarrow U V$} & $<1$ & $29 / 01 / 19$ & 30.4 & 224 & 150 & 53.7 & 374.8 \\
\hline & & $<1$ & $31 / 01 / 19$ & 30.8 & 1287 & 275 & 98.5 & 687.2 \\
\hline & & $<1$ & $01 / 02 / 19$ & 29.4 & 1349 & 250 & 89.6 & 624.8 \\
\hline & Heat + UV & 50 & $19 / 02 / 19$ & 19 & 224 & 150 & 53.7 & 374.8 \\
\hline & Heat + UV & $<1$ & $26 / 03 / 19$ & 24.4 & 354 & 200 & 71.6 & 499.7 \\
\hline & \multirow[t]{3}{*}{ Heat } & $<1$ & $29 / 01 / 19$ & 30.4 & 1452 & & & \\
\hline & & $<1$ & $31 / 01 / 19$ & 30.8 & 1287 & & & \\
\hline & & $<1$ & $01 / 02 / 19$ & 29.4 & 1349 & & & \\
\hline
\end{tabular}

$N T U$ nephelometric turbidity unit (a water turbidity measurement unit), $T{ }^{\circ} \mathrm{C}$ temperature, $U V$ ultraviolet radiation, $D_{U V I}$ direct Ultraviolet radiation, $I_{U V r l ; 2} \mathrm{UV}$ irradiance in reactors 1 and $2, I_{U V r 3} \mathrm{UV}$ irradiance in reactor 3

${ }^{a}$ In the present work, insolation means the amount of solar radiation that reaches an area of $1 \mathrm{~m}^{2}$ and the cysts were suspended in the encystment solution and stored at $4{ }^{\circ} \mathrm{C}$ until use. The viability of $A$. castellanii cysts was confirmed by the $0.4 \%$ trypan blue exclusion dye [28], just before the water inoculation and the experiment. The viability analysis consisted of mixing $10 \mu \mathrm{L}$ of the trypan blue dye with $100 \mu \mathrm{L}$ of the cysts suspension and incubating for $5 \mathrm{~min}$; Viable cysts (unstained) were counted using a Fuchs Rosenthal counting chamber in an inverted optical microscope equipped with phase contrast.

\subsection{Bacterial cultivation}

Bacteria species used to evaluate the effectiveness of the continuous-flow solar water disinfection system include Escherichia coli ATCC ${ }^{\circledR}$ 25922, Salmonella Typhimurium DT177, Enterococcus faecalis ATCC ${ }^{\circledR} 29212$ and Pseudomonas aeruginosa ATCC ${ }^{\circledR} 27853$. Previously, all bacteria were grown on different plates with Tryptic Soy agar medium for $24 \mathrm{~h}$ at $37^{\circ} \mathrm{C}$. Then two colonies of pure culture of each bacterium were aseptically inoculated in $2 \mathrm{~mL}$ of the BHI (Brain Heart Infusion) culture medium and incubated at $37{ }^{\circ} \mathrm{C}$ for $18 \mathrm{~h}$. Each bacteria species was grown separately and were washed twice with PBS just before the water inoculation.

\subsection{Water contamination}

The water was contaminated with $10^{8}$ viable cysts per liter. Viable cysts were counted using an inverted microscope equipped with phase contrast, and Fuchs Rosenthal chamber. The viability of the cysts was confirmed by exclusion staining with $0.4 \%$ trypan blue just before the use, as previously described in 2.7 .

The water was also contaminated with $10^{5}$ to $10^{6} \mathrm{CFU} /$ $\mathrm{mL}$ of each bacterial species. The bacterial density was determined by measuring the optical density of the suspension, using the BioNate $3 \mathrm{~S}$ spectrophotometer. The four species of bacteria were added simultaneously to the water, just before the experiment. The tests for disinfecting water contaminated by bacteria and by cysts were performed separately.

\subsection{Disinfection procedures}

Prior to each experiment session, the system was disinfected by distilled water flowing through the heater and UV irradiator until the water reached $80{ }^{\circ} \mathrm{C}$. The temperature was measured at the bottom of the heating tank. This temperature was chosen according to the literature that references that temperatures between 55 and $70{ }^{\circ} \mathrm{C}$ inactivate bacterial cells $[2,8,9,12]$. And $\geq 65^{\circ} \mathrm{C}$ (for $\geq 15 \mathrm{~min}$ ) inactivates cysts of Acanthamoeba spp. [5, 17].

Three different forms of disinfection were implemented:

1. Heating then UV (Heat $\rightarrow U V$ ): water was gradually heated, being pumped from the heating tank flowing continuously through the heater then returning to the heating tank, to reach $45^{\circ} \mathrm{C}$, then to $55^{\circ} \mathrm{C}$ and finally to $60{ }^{\circ} \mathrm{C}$. When the water reached each of the mentioned temperatures, it was pumped from the heating tank to the UV irradiator, where it traveled once through the reactors and then the samples were collected.

2. Heat and UV (Heat $+U V)$ : the water was heated at the same time as it was irradiated by UVA and UVB, being 
pumped from the heating tank, flowing continuously through the heater and from it to the UV irradiator, then returning to the heating tank until reaching the desired temperature.

3. Heat: the water was gradually heated, being pumped from the heating tank, flowing continuously through the heater and returning to the heating tank until the desired temperature was reached.

Details on the turbidity and variations in the water temperature per treatment, as well as the time that the water remained flowing through the system after reaching the desired temperature (contact time) before sample collection, are shown in Table 2.

When the desired water temperature was reached, the heater absorber was defocused and covered with aluminum foil (in the Heat $\rightarrow U V$ and Heat + UV treatments) or the water flow was interrupted (in the heat treatment), for the desired time. Cyst and bacterial tests were performed separately. All experiments were performed four times each, in triplicates.

\subsection{Samples collection and transport conditions}

$45 \mathrm{~mL}$ of composite samples were collected in $50 \mathrm{~mL}$ falcon tubes. The samples were immediately cooled in a water bath at room temperature $\left(24{ }^{\circ} \mathrm{C} \pm 2\right)$, protected from sunlight, and kept under these conditions until the analyzes were performed within $2.5 \mathrm{~h}$.

\subsection{Cyst viability analysis}

The water samples were centrifuged (3000 rpm for $10 \mathrm{~min}$ ) discarding the supernatant, and the pellet was suspended in $150 \mu \mathrm{L}$. Spots of $50 \mu \mathrm{L}$ of the sediment were seeded in the center of each of three quadrants of the fresh non-nutrient agar (NNA) containing a heat-inactivated Escherichia coli

Table 2 Details of testing and sampling variations

\begin{tabular}{lllll}
\hline Target & Treatment & $\begin{array}{l}\text { Water } \\
\text { turbidity } \\
(\mathrm{NTU})\end{array}$ & $\begin{array}{l}\text { Temperature } \\
\left({ }^{\circ} \mathrm{C}\right)\end{array}$ & $\begin{array}{l}\text { Contact time } \\
(\mathrm{min})\end{array}$ \\
\hline Bacteria & Heat $\rightarrow \mathrm{UV}$ & $<1$ & $45,55,60$ & 0.5 \\
& Heat $+\mathrm{UV}$ & $<1$ & & \\
& & 50 & & \\
& Heat & $<1$ & & \\
Cysts & Heat $+\mathrm{UV}$ & $<1$ & $60,65,70^{\mathrm{a}}$ & $0.5,10$ \\
& & 50 & & \\
& Heat & $<1$ & & \\
\hline
\end{tabular}

The contact time refers to the minutes that the water remained flowing through the system after reaching the corresponding desired temperature

$N T U$ nephelometric turbidity unit

${ }^{\mathrm{a}}$ Only $0.5 \mathrm{~min}$ of contact time $\left(70{ }^{\circ} \mathrm{C}\right)$ layer $\left(56^{\circ} \mathrm{C}\right.$ for $\left.2 \mathrm{~h}\right)$ previously spread. After spots drying, the plates were incubated at $30^{\circ} \mathrm{C}$, and checked every day for 20 days.

Five randomized microscopy fields (using 100× magnification) were found on each NNA agar quadrant, in the area where the spot was deposited, to count the number of cysts, and to check for the absence or presence of trophozoites. If present, the number of trophozoites observed per microscopy field were counted and the arithmetic mean was calculated. Microscopy fields with higher density and homogeneous distribution of cysts or trophozoites were used.

Only the values of the trophozoites were used since we only need to determine the viability of the cysts, recovering trophozoites from previously treated cysts. The unchanged values of the cysts served to confirm that there was no growth in the plates in which the trophozoites were not detected during the entire incubation period.

No mathematical model was used to relate the number of trophozoites observed per microscopic field, with the initial number of cysts. Our aim was to find out if the cysts were viable after treatment and if the number of trophozoites recovered from the viable cysts decreased with increasing temperature and exposure time in the different treatments.

\subsection{Viability analysis of bacteria}

Samples were subjected to serial dilutions as described in the literature [29]. The drop plate sowing technique was used to inoculate selective agar, EMB (eosin methylene/blue agar-levine), XLD (xylose deoxycholate agar), bile esculin and cetrimide agar plates for Escherichia coli, Salmonella Typhimurium, Enterococcus faecalis and Pseudomonas aeruginosa, respectively. The plates were incubated at $35^{\circ} \mathrm{C}$, and counting CFU was performed after $18 \mathrm{~h}$ of incubation. The non-growing plates remained in the incubator for an additional $18 \mathrm{~h}$ being monitored. The dilution that showed the highest bacterial growth, was chosen and the CFU value was multiplied by the respective dilution factor.

\subsection{Data analysis}

The normality of data was verified by the Shapiro-Wilk test at $5 \%$ level of probability, then were analysed by ANOVA followed by Tukey post-test. Differences were considered significant when $P<0.05$. Statistical analysis was performed with the BioEstat 5.0 software, and GraphPad prism 8.02 software were used for plotting graphs.

Arithmetic mean was calculated between the daily trophozoite counts of the triplicates. The trophozoite values are presented as geometric averages of the counts between the following intervals of days $1-6,7-10,11-14,17-18$ and $19-20$. 


\section{Results and discussion}

In the present study, a continuous-flow solar water disinfection system was developed aiming to propose an alternative solution to the problem of smaller amount of water treated per day through conventional SODIS. It was designed to utilize the synergistic effect of solar heat, UV-A and UV-B to inactivate microorganisms present in water. To that end, a solar heater and a UV irradiator were designed and built (Fig. 3).

The system has been tested to inactivate $A$. castellanii cysts, which are resistant to many adverse environmental conditions such as chemical, physical and radiological [5]. This resistance is attributed to its double-thick wall containing cellulose [5, 17, 30]. Acanthamoeba spp. have been implicated in the development of environmental resilience and virulence of a wide range of bacterial and viral pathogens and their prevalence in chlorinated drinking water distribution systems $[16,18,39]$.

\subsection{Optical properties of the system}

The average reflectance value of the common glass mirror for infrared (IR) radiation (80.8\%) was slightly higher than of the metallic aluminum polyester adhesive (79.2\%). Despite this, the aluminum metallic polyester adhesive was chosen because it has a higher UV reflectance and is cheaper and easier to use. The reflectance of the tested stainless steel was $68.4 \%$ (Fig. 4).

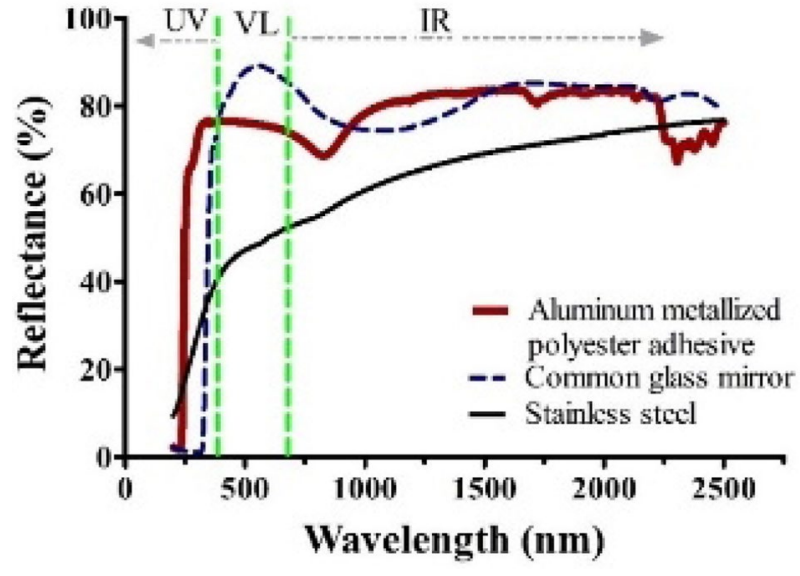

Fig. 4 Reflectance of tested materials for visible light (VL), infrared (IR) and ultraviolet (UV) radiation. The reflectance of two samples of each material was measured and an average was calculated

The average reflectance of aluminum metallized polyester-adhesive for the UV spectrum was $74.7 \%$ (Fig. 5).

The high purity quartz sample presented an average transmittance of 91.8 and $91.2 \%$ for UVA and UVB, respectively. Despite this, it was not used because it did not have a cost-benefit advantage, as it is very expensive, which would make the system expensive. The wall of the chosen quartz tube showed an average transmittance value for UVA and UVB of 87.2 and $83.3 \%$, respectively (Fig. 6).

This system has a great advantage when compared to the conventional SODIS process, which consists of exposing



Fig. 3 Overview of the continuous water flow solar disinfection system operating during the tests. In the tests, only one tank $(10 \mathrm{~L}$ heating tank) was used, from which water was pumped, flowing through the heater and UV irradiator, and returning to the heating tank. At the end of each treatment cycle, the water flow was interrupted and the treated water was exchanged for another one 


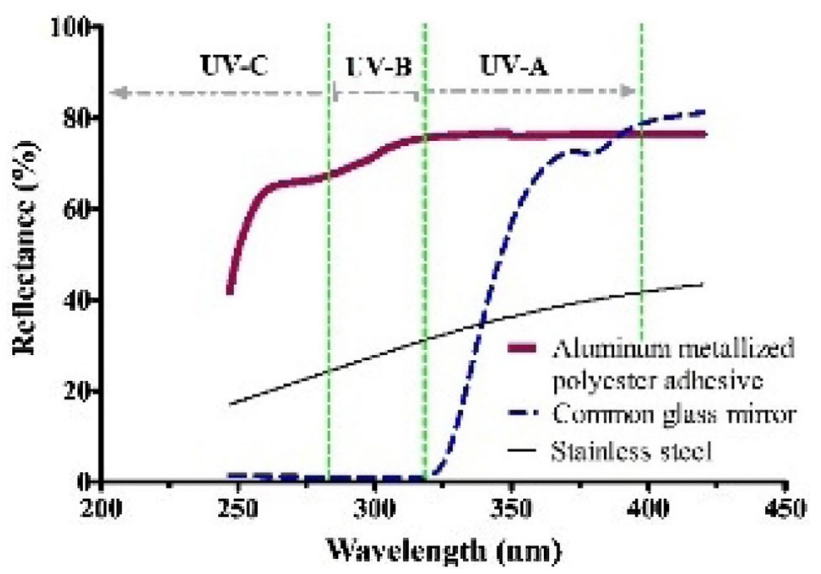

Fig. 5 Reflectance rate of materials tested for the wavelength range of ultraviolet radiation. The reflectances of two samples of each material were measured and an average was calculated

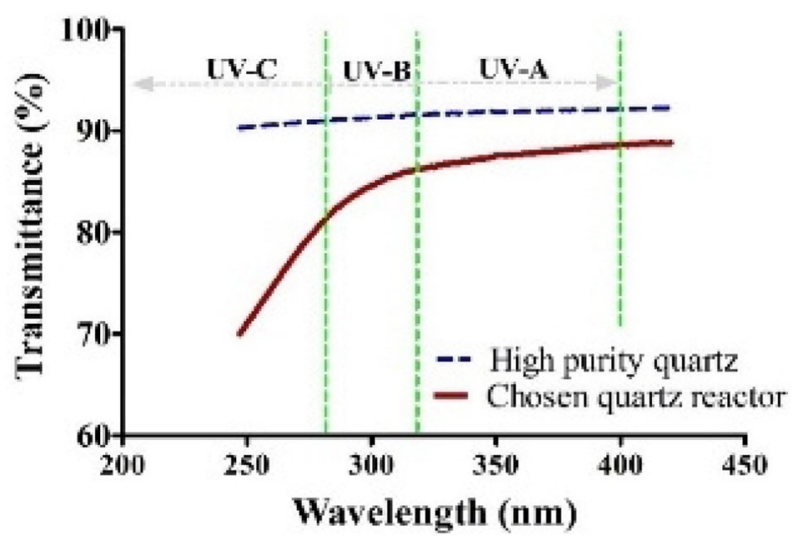

Fig. 6 Transmittance rates of the quartz tubular reactor wall and the high purity quartz sample for ultraviolet radiation The transmittances of two samples from the wall of the quartz tube and the high purity quartz were measured and then an average was calculated

PET plastic bottles containing water to direct sunlight for $6 \mathrm{~h}$ on sunny days, on cloudy days ( $\geq 50 \%$ cloud cover), $12 \mathrm{~h}$ of exposure are required [7]. In conventional SODIS, the amount of treated water is conditioned by the availability of PET bottles, which in addition to not being accessible in rural areas, are essentially opaque to UVB radiation, which is at least two digits in magnitude more biocidal than UVA $[7,8,10]$.

\subsection{System operation}

The air temperature at the time of the experiment ranged from 24 to $30.8{ }^{\circ} \mathrm{C}$. Insolation ranged from 224 to $1471 \mathrm{~kJ} /$ $\mathrm{m}^{2}$, while direct UV radiation ranged from 150 to $250 \mathrm{~mW} /$

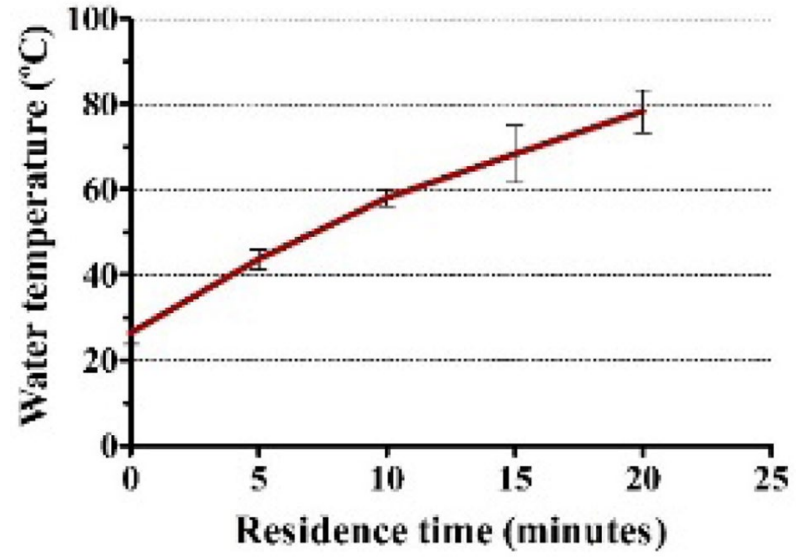

Fig. 7 Water temperature rates per residence time in the system. The measurements were carried out with $10 \mathrm{~L}$ of water

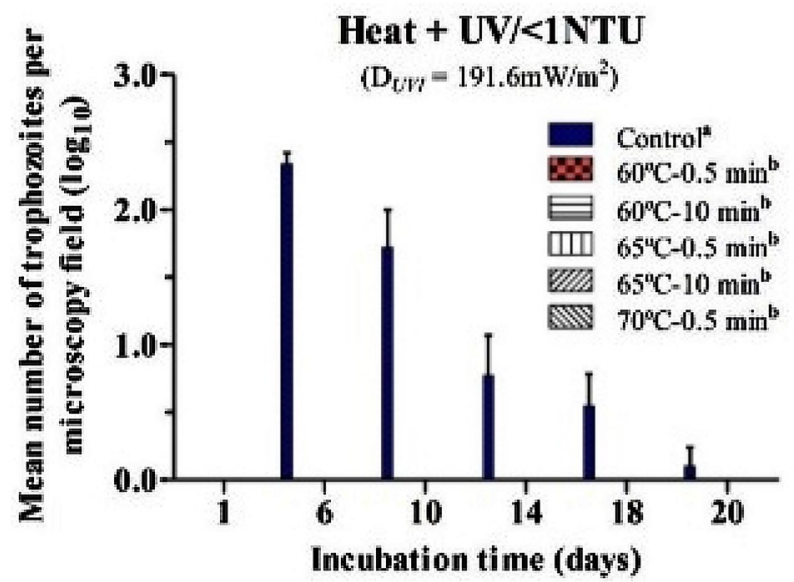

Fig. 8 Average number of trophozoites recovered from A. castellanii cysts treated by exposure to the synergistic effect of heat and ultraviolet radiation in water with low turbidity (Heat $+\mathrm{UV} /<1 \mathrm{NTU})$. The values are presented as geometric means of the trophozoites counted by microscopic field, daily for 20 days of incubation. The approaches marked with the same letter are not significantly different $(P<0.05)$

$\mathrm{m}^{2}$. The estimated values of concentrated UV radiation within quartz reactors 1,2 and 3 are presented in Table 1.

The average water temperature before treatment was $26.4{ }^{\circ} \mathrm{C} .10 \mathrm{~L}$ of water were processed at a time. A rapid increase in temperature was observed in the first $10 \mathrm{~min}$, reaching an average of $58.0^{\circ} \mathrm{C}$. The quickness of temperature increase after 15 min was influenced by cloudiness and wind. On sunny and light windy days, temperatures of up to $83^{\circ} \mathrm{C}$ were reached within $20 \mathrm{~min}$ (Fig. 7).

\subsection{Cyst inactivation}

The visualization of trophozoites in most control plates occurred $24 \mathrm{~h}$ after the start of incubation, in some plates it 
occurred within $48 \mathrm{~h}$. No trophozoites were recovered from A. castellanii cysts in all Heat $+\mathrm{UV} /<1 \mathrm{NTU}$ treatment approaches in all replicates of the experiment (Fig. 8).

When viable cysts of Acanthamoeba spp. are inoculated into a bacterial layer on fresh agar plates, trophozoite visualization normally occurs after $24 \mathrm{~h}$ or up to 3 days. In some cases, it may take longer, however, usually no more than 9 days $[5,16]$. In the present study, the plates were monitored for 20 successive days, that is why it can be safely stated that cysts that were not excysted during this period were not viable.

Our data show that the cysts were not cultivable, even in samples collected $30 \mathrm{~s}$ after the water reached $60{ }^{\circ} \mathrm{C}$, in tests with low turbidity water. These results showed the importance of the synergistic effect of UV and heat for the inactivation of $A$. castellanii cysts, as already demonstrated for bacteria $[7,8]$.

The literature shows heterogeneous data on the thermal inactivation of FLA cysts. Inactivation of A castellanii cysts was reported at $80^{\circ} \mathrm{C}$ for $10 \mathrm{~min},[31] 70{ }^{\circ} \mathrm{C}$ for $\geq 2 \mathrm{~min}$, [17] $65^{\circ} \mathrm{C}$ for $>5 \mathrm{~min}$ [5] and of A. castellanii-30,010 (the same strain used in the present study) in $65{ }^{\circ} \mathrm{C}$ for $10 \mathrm{~min}$ [32]. The diversity of results can be attributed to differences in intrinsic characteristics of each strain and the lack of inactivation assay standards [17, 18]. Although this makes it difficult to carry out a simple comparison, it should be noted that our data are in line with the findings of the referenced authors and still show greater efficiency of the system, since the same result was obtained at relatively lower temperatures with less exposure time. The greater effectiveness is attributed to the synergistic effect of heat and UVA and UVB radiation $[7,8]$.

No trophozoites were recovered in most Heat $+\mathrm{UV} / 50 \mathrm{NTU}$ treatment approaches. In two of the four replications of the $60{ }^{\circ} \mathrm{C}+\mathrm{UV}-0.5 / 50 \mathrm{NTU}$ approach, the trophozoites were recovered from the cysts and were visualized from the sixth day of incubation (Fig. 8). The average number of trophozoites recovered from the cysts in the $60{ }^{\circ} \mathrm{C}+\mathrm{UV}-0.5 / 50 \mathrm{NTU}$ approach differed significantly from the control but was not significantly different from 0 , by the Student's $t$ test $(P<0.05)$ (Fig. 9).

The results obtained in the heat treatment are similar to those of the heat + UV/50NTU treatment, however, in the heat treatment, the trophozoites were visualized from the fifth day of incubation (Fig. 10).

The similarity of the data in the $60{ }^{\circ} \mathrm{C}+\mathrm{UV}-0.5 / 50 \mathrm{NTU}$ and $60{ }^{\circ} \mathrm{C}-0.5$ approaches can be attributed to the fact that both results are essentially due to the effect of heat. Although UVA and UVB are present in the Heat + UV/50NTU treatment, their effect was not significant due to high turbidity. Turbidity reduces water transmittance; therefore, the greater the turbidity, the less likely the UV will reach the microorganisms dispersed in the water [26, 27]. The authors agree

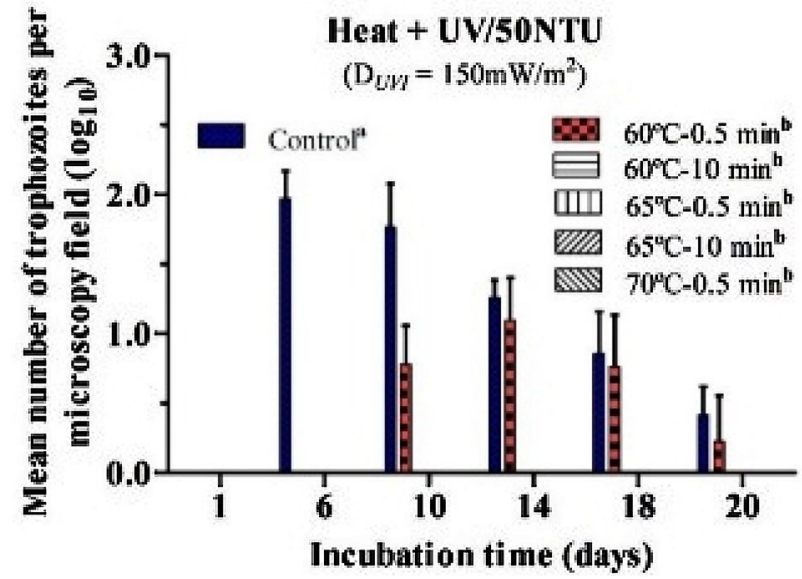

Fig. 9 Average number of trophozoites recovered from A. castellanii cysts treated by exposure to the synergistic effect of heat and ultraviolet radiation in water with high turbidity (Heat + UV/50NTU). The values are presented as geometric means of the trophozoites counted by microscopic field, daily for 20 days of incubation. The approaches marked with the same letter are not significantly different $(P<0.05)$



Fig. 10 Average number of trophozoites recovered from A. castellanii cysts treated by exposure only to the effect of heat in water with low turbidity (Heat/ $<1 \mathrm{NTU})$. The values are presented as geometric means of the trophozoites counted in a microscopic field, daily for 20 days of incubation. The approaches marked with the same letter are not significantly different $(P<0.05)$

that turbidity rates $>25$ NTU compromise the effectiveness of conventional SODIS [26, 27]. Despite this, the inactivation of cysts in water with high turbidity (50NTU) was achieved at $60{ }^{\circ} \mathrm{C}$ after $10 \mathrm{~min}$ of exposure time.

The late excystment observed in this work is in agreement with other authors, who reported the excystment after three days of $A$. castellanii cysts exposed to $250 \mathrm{~K}$ rads of $\gamma$ radiation, the authors also reported that the cysts were resistant to exposure to $800 \mathrm{~mJ} / \mathrm{cm}^{2}$ of UVB radiation for $2 \mathrm{~h} \mathrm{[5].} \mathrm{Our}$ 
data obtained in tests prior to the present study (data not published), performed indoors, according to the procedures described in the literature, [33] confirmed the findings of these authors. In our study, A. castellanii cysts were resistant to exposure to $243 \mu \mathrm{W} / \mathrm{cm}^{2}$ of UVC radiation $(\lambda=254 \mathrm{~nm})$, at room temperature for $2 \mathrm{~h}$, but were sensitive to the synergistic effect of UVC radiation and $60{ }^{\circ} \mathrm{C}$ for $5 \mathrm{~min}$.

A. castellanii cysts have a wall composed of two layers both made of cellulose and other biomolecules [30], which is why they are opaque to UV radiation. This prevents direct damage to the cell by radiation energy and/or by the formation of reactive oxygen species (ROS) in the cytoplasm, leading to the cell inactivating in the event that such damage cannot be quickly repaired by the cell [6-8]. For this reason, it is safe to say that the mechanism of inactivation of A. castellanii cysts by $\mathrm{UV}$ is indirect, due to the action of reactive oxidants such as $\mathrm{OH}^{-}$and $\mathrm{O}_{3}$, formed during water photolysis [30, 34, 35, 35]. These oxidants react quickly non-selectively with many cyst biomolecules, starting with the components of the ectocyst, the substances present in the space between the layers of the wall, the endocyst, until reaching the intracellular biomolecules $[30,34,36]$.

\subsection{Bacteria inactivation}

As expected, no CFU/100 mL of all tested bacterial species was detected in approaches involving $60^{\circ} \mathrm{C}$ (with or without UV) in all treatments. In the tests performed at $55^{\circ} \mathrm{C}$, inactivation of all bacteria was obtained or a statistically significant reduction $(P<0.05)$. When the temperature of $45^{\circ} \mathrm{C}$ was used, a statistically significant and sometimes insignificant reduction of CFU/100 mL was obtained (Fig. 11).

The average numbers of UFC/100 mL detected did not show statistically significant differences between the Heat + UV/50NUT and Heat $\rightarrow$ UV treatments by ANOVA followed by Tukey post-test.


Fig. 11 Average number of bacterial colony-forming units (CFU) detected per $100 \mathrm{~mL}$ of sample collected in each treatment. *Significantly different from the corresponding control 
Our data suggest that the Heat $\rightarrow \mathrm{UV}$ treatment is much more effective (Fig. 11a) than the other treatments since the death of all bacteria was observed in the approaches involving 55 and $60{ }^{\circ} \mathrm{C}$. In the Heat $+\mathrm{UV} /<1 \mathrm{NTU}$ treatment, the same result was obtained only in the approach involving $60{ }^{\circ} \mathrm{C}$; at $55{ }^{\circ} \mathrm{C}$ an expressive reduction of UFC/100 mL was achieved (Fig. 11b). These findings confirm that the exposure time to heat is decisive to achieve bacterial inactivation [9], and confirm the importance of the synergistic effect of UV radiation and heat to inactivate bacteria in a short exposure time [7, 8, 34].

The similarity of the data obtained in the Heat + UV/50NTU and Heat treatments (Fig. 11c, d) can be attributed to the fact that both result essentially from the effect of heat, as previously explained for cysts [26, 27]. Our data are in agreement with the findings of other authors who reported inactivation of $E$. coli at $60^{\circ} \mathrm{C}$, using SOPAS-based systems [13, 14]. However, in most studies, temperatures above $60{ }^{\circ} \mathrm{C}$ were needed to achieve bacterial inactivation, for example, E. coli inactivation was obtained at a temperature of $87{ }^{\circ} \mathrm{C}$ [12], or $\geq 66{ }^{\circ} \mathrm{C}$ were needed to inactivate Legionella spp. Pseudomonas spp. and Salmonella spp. [2] The E. coli inactivation has also been reported at $55^{\circ} \mathrm{C}$ for $\geq 120 \mathrm{~min}$, or at $60^{\circ} \mathrm{C}$ for $\geq 45 \mathrm{~min}$ or at $70{ }^{\circ} \mathrm{C}$ for $\geq 15 \min$ [9].

In the present study, using the synergistic effect of solar $\mathrm{UV}$ and heat, the inactivation of all bacterial species tested in water with low turbidity was achieved from $55^{\circ} \mathrm{C}$ and in water with high turbidity was achieved at $60{ }^{\circ} \mathrm{C}$, for $30 \mathrm{~s}$ of exposure time. This shows the higher performance of this system in relation to the others reported [2, 12-14], as well as in relation to the conventional SODIS process $[1,3,9]$.

\subsection{System productivity}

As far as we know, the continuous-flow system designed and built in the present work has certain peculiar characteristics in its configuration, which allows it to concentrate the IR, UVA and UVB radiation and make it converge on the water in a continuous way, allowing the inactivation of $A$. castellanii cysts. The system allows the tracking of solar radiation in two axes and can be scaled according to the desired flow rate, and this increases its productivity. The design of the system allows water to reflow through the system during the disinfection process for the time necessary until optimal disinfection conditions are achieved. This allows the system to maintain its disinfection effectiveness even on less sunny days or hours, such as in the early morning hours, at dusk, or on partly cloudy days; however, its productivity will be higher in the sunniest moments of the day.

In the present study, using the prototype built on a smaller scale, average productivity of $40 \mathrm{~L} / \mathrm{h}$ was achieved, considering that the water should be irradiated while heated to $60^{\circ} \mathrm{C}$, keeping it in circulation by the radiator for another $10 \mathrm{~min}$ $\left(60{ }^{\circ} \mathrm{C}+\mathrm{UV}-10\right)$. Average production of $360 \mathrm{~L}$ of processed water per day was achieved on sunny days, operating from 8:30 a.m. to 4:30 p.m.

Various batch or continuous flow treatment systems with different configurations based on SOPAS are described in the literature, treating water at temperatures ranging from 55 to $87^{\circ} \mathrm{C}$, treating different amounts of water [2, 12-14]. For example, a pasteurizer based on a parabolic cylindrical concentrator was tested, in which $E$. coli inactivation was achieved at $87{ }^{\circ} \mathrm{C}$, producing a maximum of $66 \mathrm{~L}$ of water on sunny days [12]. Carielo et al. and Tiba [13] used a system based on a flat heat exchanger, reaching a maximum production of $30 \mathrm{~L}$ of water per day on sunny days. Reyneke et al. [2] tested a pasteurization system for rainwater stored in a tank, which was based on a flat heat exchanger, where inactivation of fecal coliform was achieved. They estimated that about $16.25 \mathrm{~kg} / \mathrm{h}^{-1}$ and $12.8 \mathrm{~kg} / \mathrm{h}$ of pasteurized water were produced at a temperature of 58 and $66^{\circ} \mathrm{C}$. Domingos et al. [14] tested an automated parabolic solar disk for disinfection of continuous flow water by pasteurization. Average temperatures between 58 and $65^{\circ} \mathrm{C}$ inactivated $E$. coli in the water at a flow rate of $63 \mathrm{~L} / \mathrm{h}$, between 10:00 a.m. and 15:00 p.m. on sunny days. Mbonimpa et al. [10] built a prototype system for continuous flow UVB solar disinfection, in which a significant reduction in $E$. coli was obtained after $54.5 \mathrm{~min}$ of exposure. Gill and Price [11] implemented a continuous solar UV disinfection system. Fecal coliform inactivation was achieved in the summer at a flow rate of $10.4 \mathrm{~L} / \mathrm{min}$.

It is important to note that the systems presented were tested for bacterial cell inactivation, and their productivity was estimated with these microorganisms as targets, which are much more sensitive than $A$. castellanii cysts [2, 12-14]. Its ability to inactivate forms of resistance to environmental adversities, such as $A$. castellanii cysts, has not been evaluated. In this regard, the system tested in this work has a comparative advantage. The inactivation of trophozoites and cysts of $A$. castellanii in water is desirable because in addition to being opportunistic pathogens, they have been implicated in the pseudo-resistance of bacteria in water, including chlorinated water $[15,18,19]$. The mechanism by which this occurs and its consequences for the increase of amoebic and bacterial pathogenicity is widely reported in the literature $[15,18,37]$. Briefly, in the environment, trophozoites phagocytize bacteria, and many of them are amoeba-resistant microorganisms (ARM) that is, they are able to escape the path of intracellular digestion and survive and multiply within the amoebic cell. When environmental conditions become unfavorable, amoebae become encysted and bacteria remain viable and protected within the cysts. Cysts are resistant to various disinfectants, including chlorine; therefore, for example, bacteria dispersed in chlorinated water die; however, those internalized in the amoeba 
survive, and when the effect of residual chlorine ceases, bacteria can quickly re-colonize the water $[18,19]$. It should be noted that $19 \%$ of the 539 bacterial species described as pathogens for humans and animals have been reported as ARM [18].

The system's effectiveness against $A$. castellanii cysts can be extrapolated to other protozoa that today are indicators of water potability and that are also known to be resistant including to chlorination (for example, Cryptosporidium, Giardia and Toxoplasma) which are small in size, so they may not be retained in some filters [33].

The other advantage refers to the fact that this system can be used to provide drinking water for several families. Considering the productivity of a small system, as tested in the present study ( $360 \mathrm{~L} /$ day), and the realistic estimate of the World Health Organization according to which an individual needs at least $5 \mathrm{~L} /$ day of drinking water to drink and prepare food the system is able to provide drinking water for 14 families with 5 members. Some systems of larger dimensions can be installed in small stations for solar water treatment in gravitational flow, the treated water can be stored in reservoirs, which allows even on cloudy days the population continues to have access to treated water.

A system built with perennial material, with dimensions equal to the prototype tested in this work, has an average cost of 400 USD, with an estimated useful life of at least 5 years.

Some improvements are desirable to increase the productivity of the system, such as optimizing the size of the heater and installing thermostatic valves in the absorber. The use of high-performance mirrors and absorbers, the use of heat from treated water to preheat raw water, and the automation of two-axis solar tracking are also important improvements.

\section{Conclusions}

This study aimed to develop and test a continuous flow system for solar water disinfection, to overcome the limitation of a small volume of disinfected drinking water per day through the conventional SODIS process.

The system uses the synergistic effect of heat and UVA and UVB to inactivate microorganisms present in water, and is capable of inactivating bacteria and cysts of $A$. castellanii, in water with low $(<1 \mathrm{NTU})$ and high (50 NTU) turbidity. Inactivation of $A$. castellanii cysts or bacteria in water with $<1 \mathrm{NTU}$ was achieved in less time $\left(60{ }^{\circ} \mathrm{C}+\mathrm{UV} / 0.5 \mathrm{~min}\right)$ or at lower temperatures $\left(55^{\circ} \mathrm{C}+\mathrm{UV} / 0.5 \mathrm{~min}\right)$. To achieve the same result in water with $50 \mathrm{NTU}$, a longer contact time $\left(60^{\circ} \mathrm{C}+\mathrm{UV} / 10 \mathrm{~min}\right)$ or a higher temperature $\left(60^{\circ} \mathrm{C}+\mathrm{UV} / 0.5 \mathrm{~min}\right)$ was necessary.

The system was able to perform complete disinfection of water contaminated simultaneously by to four different bacterial species (E. coli, Salmonella Typhimurium, E. faecalis and $P$. aeruginosa) at a density of $5-6 \log _{10}$ per $\mathrm{mL}$ of each bacterium, making water drinkable in accordance with WHO's drinking-water guidelines. Complete disinfection with a reduction of $8 \log _{10}$ per liter of $A$. castellanii cysts was also achieved, thus eliminating the health risk associated with this protozoan in drinking water. This result can be extrapolated to (oo)cysts of other pathogenic protozoa with comparable or lower resistance, such as Acanthamoeba spp., Giardia spp., N. fowleri, C. parvum and Entamoeba histolytica.

The system overcomes the limitation of conventional SODIS, and the prototype on an experimental scale tested in the present study is capable of processing $1 \mathrm{~L}$ of drinking water every 90s. The system has the potential to be applied as an alternative to the large-scale public water supply.

Acknowledgements To CAPES (GCUB/ProAfri/n001/2018) for the scholarship for Beni J.M. Chaúque and the PPGMAA for some financial support in the construction of the prototype.

\section{Compliance with ethical standards}

Conflict of interest The authors declare that they have no conflict of interest.

\section{References}

1. McGuigan, K. G., Conroy, R. M., Mosler, H., Du Preez, M., Ubomba-Jaswa, E., \& Fernandez-Ibañez, P. (2012). Solar water disinfection (SODIS): a review from bench-top to roof-top. Journal of Hazardous Materials, 235(236), 29-46.

2. Reyneke, B., Cloete, T. E., Khan, S., \& Khan, W. (2018). Rainwater harvesting solar pasteurization treatment systems for the provision of an alternative water source in peri-urban informal settlements. Environmental Science Water Research and Technology, 4, 291-302.

3. Pichel, N., \& VivarM, M. (2019). Fuentes, the problem of drinking water access: a review of disinfection technologies with an emphasis on solar treatment methods. Chemosphere, 218, 1014-1030.

4. McGuigan, K. G., Samaiyar, P., Du Preez, M., \& Conroy, R. M. (2011). High compliance randomized controlled field trial of solar disinfection of drinking water and its impact on childhood diarrhea in rural Cambodia. Environmental Science and Technology, 45(18), 7862-7867.

5. Aksozek, A., Mcclellan, K., Howard, K., Niederkorn, J. Y., \& Alizadeh, H. (2002). Resistance of Acanthamoeba castellanii cysts to physical, chemical, and radiological conditions. Journal of Parasitology, 88(3), 621-623.

6. Vivar, M., Pichel, N., Fuentes, M., \& López-Vargas, A. (2017). Separating the UV and thermal components during real-time solar disinfection experiments: the effect of temperature. Solar Energy, 146, 334-341.

7. Castro-Alférez, M., Polo-López, M. I., \& Fernández-Ibáñe, P. (2016). Intracellular mechanisms of solar water disinfection. Scientific Reports, 6, 38145.

8. Castro-Alférez, M., Polo-López, M. I., Marugán, J., \& FernándezIbáñez, P. (2017). Mechanistic modeling of UV and mild-heat synergistic effect on solar water disinfection. Chemical Engineering Journal, 316, 111-120. 
9. KulkarniA, A., Kapley, R. S., Dhodapkar, P., \& Nagababu, S. R. (2019). Plasmonics driven engineered pasteurizers for solar water disinfection (SWADIS). Journal of Hazardous Materials, $369,474-482$

10. Mbonimpa, E. G., Vadheim, B., \& Blatchley, E. R., III. (2012). Continuous-flow solar UVB disinfection reactor for drinking water. Water Research, 46, 2344-2354.

11. Gill, L. W., \& Price, C. (2010). Preliminary observations of a continuous flow solar disinfection system for a rural community in Kenya. Energy, 35(12), 4607-4611.

12. Bigoni, R., Kötzsch, S., Sorlini, S., \& Egli, T. (2014). Solar water disinfection by a parabolic trough concentrator (PTC): flow-cytometric analysis of bacterial inactivation. Journal of Cleaner Production, 67, 62-71.

13. D. S. G. Carielo C. TIBA, G. M. T. . (2016). Calazans, Solar pasteurizer for the microbiological decontamination of water. Renew Energy, 87, 711-719.

14. Domingos, M., Sanchez, B., Vieira-DA-Motta, O., Samarão, S. S., \& Canela, M. C. (2018). A new automated solar disc for water disinfection by pasteurization. Photochemical and Photobiological Sciences, 18, 905-911.

15. Thomas, V., Bouchez, T., Nicolas, V., Robert, S., Loret, J. F., \& Lévi, Y. (2004). Amoebae in domestic water systems: resistance to disinfection treatments and implication in Legionella persistence. Journal of Applied Microbiology, 97, 950-963.

16. Sriram, R., Shoff, M., Booton, G., Fuerst, P., \& Visvesvara, G. S. (2008). Survival of Acanthamoeba cysts after desiccation for more than 20 years. Journal of Clinical Microbiology, 46(12), 4045-4048.

17. Cervero-Aragó, S., Rodríuez-Marínez, S., Canals, O., Salvadó, H., \& Araujo, R. M. (2013). Effect of thermal treatment on freeliving amoeba inactivation. Journal of Applied Microbiology, 116(3), 1364-5072.

18. Thomas, V., McDonnell, G., Denyer, S. P., \& Maillard, J. Y. (2010). Free-living amoebae and their intracellular pathogenic microorganisms: risks for water quality. FEMS Microbiology Reviews, 34, 231-259.

19. Berk, S. G., Faulkner, G., Garduno, E., Joy, M. C., OrtizJimenez, M. A., \& Garduno, R. A. (2008). Packaging of live Legionella pneumophila into pellets expelled by Tetrahymena spp. does not require bacterial replication and depends on a Dot/ Icm-mediated survival mechanism. Applied and Environmental Microbiology, 74, 2187-2199.

20. Castro-Alférez, M., Polo-López, M. I., Marugán, J., \& Fernández-Ibáñez, P. (2018). Validation of a solar-thermal water disinfection model for Escherichia coli inactivation in pilot scale solar reactors and real conditions. Chemical Engineering Journal, 331, 831-840.

21. Ghodbane, M., Boumeddane, B., Said, Z., \& Bellos, E. (2019). A numerical simulation of a linear Fresnel solar reflector directed to produce steam for the power plant. Journal of Cleaner Production, 231, 494-508.

22. Rashid, A. (2018). Use of a parabolic trough collector in the Kingdom of Bahrain conditions for water desalination in sustainability and resilience conference: mitigating risks and emergency planning. KnE Engineering, 3, 122-134.

23. S. G. Kandlikar, \& S. K. Vij. (1978) Geometrical aspects of a cylindrical parabolic collector. In Proceedings of the International Solar Energy Congress, New Delhi, India, pp. (12541258). Oxford: Pergamon Press

24. Norouzi, A. M., Siavashi, M., \& Oskouei, M. H. K. (2020). Efficiency enhancement of the parabolic trough solar collector using the rotating absorber tube and nanoparticles. Renewable Energy, 145, 569-584.

25. Salvadori, G., Leccese, F., Lista, D., Burattini, C., \& Bisegna, F. (2020). Use of smartphone apps to monitor human exposure to solar radiation: comparison between predicted and measured UV index values. Environmental Research, 183, 109274.

26. Gómez-Couso, H., Fontán-Saínz, M., Sichel, C., FernándezIbáñez, P., \& Ares-Mazás, E. (2009). Efficacy of the solar water disinfection method in turbid waters experimentally contaminated with Cryptosporidium parvum oocysts under real field conditions. Science of the Total Environment, 14(6), 620-627.

27. Dawney, B., \& Pearce, J. M. (2012). Optimizing the solar water disinfection (SODIS) method by decreasing turbidity with $\mathrm{NaCl}$. Journal of Water Sanitation Hygience and Development, 2(2), 87-94.

28. Hammoudeh, S. M., Hammoudeh, A. M., \& Hamoudi, R. (2019). High-throughput quantification of the effect of DMSO on the viability of lung and breast cancer cells using an easy-touse spectrophotometric trypan blue-based assay. Histochemistry and Cell Biology, 152(1), 75-84.

29. Garre, A., Egea, J. A., Esnoz, A., Palop, A., \& Fernandez, P. S. (2019). Tail or artefact? Illustration of the impact that uncertainty of the serial dilution and cell enumeration methods has on microbial inactivation. International Food Research Journal, 119, 76-83.

30. Garajová, M., Mrva, M., Vaškovicová, N., Martinka, M., Melicherová, J., \& Valigurová, A. (2019). Cellulose fibrils formation and organisation of cytoskeleton during encystment are essential for Acanthamoeba cyst wall architecture. Scientific Reports, 9, 4466.

31. Ludwig, I. H., Meisler, D. M., Rutherford, I., Bican, F. E., Langston, R. H., \& Visvesvara, G. S. (1986). Susceptibility of Acanthamoeba to soft contact lens disinfection systems. Investigaaive Ophthalmology and Visual Science, 27, 626-628.

32. Coulon, C., Collignon, A., McDonnell, G., \& Thomas, V. (2010). Resistance of Acanthamoeba cysts to disinfection treatments used in health care settings. Journal of Clinical Microbiology, 48, 2689-2697.

33. Heaselgrave, W., \& Kilvington, S. (2011). The efficacy of simulated solar disinfection (SODIS) against Ascaris, Giardia, Acanthamoeba, Naegleria, Entamoeba and Cryptosporidium. Acta Tropica, 119, 138-143.

34. Coohill, T. P., \& Sagripanti, J. L. (2008). Overview of the Inactivation by $254 \mathrm{~nm}$ ultraviolet radiation of bacteria with particular relevance to biodefense. Journal of Photochemistry and Photobiology, 84(5), 1084-1090.

35. Mora, A. S., \& Mohseni, M. (2018). Temperature dependence of the absorbance of $185 \mathrm{~nm}$ photons by water and commonly occurring solutes and its influence on the VUV advanced oxidation process. Environmental Science: Water Research and Technology, 4, 1303-1309.

36. Chung, K.-H., Kim, B.-J., Kim, S.-J., Park, Y.-K., \& Jung, S.-C. (2020). Correlation of hydrogen generation and optical emission properties of plasma in water photolysis on perovskite photocatalysts. International Journal of Hydrogen Energy, 45(15), 8595-8604.

37. Remucal, C. K., \& Manley, D. (2016). Emerging investigators series: the efficacy of chlorine photolysis as an advanced oxidation process for drinking water treatment. Environmental Science: Water Research and Technology, 2, 565-579.

38. Nakagawa, H., Koike, N., Ehara, T., Hattori, T., Narimatsu, A., Kumakura, S., \& Goto, H. (2019). Corticosteroid eye drop instillation aggravates the development of Acanthamoeba keratitis in rabbit corneas inoculated with Acanthamoeba and bacteria. Scientific Reports, 9(1), 12821.

39. WHO (2011). Guidelines for drinking-water quality, 4th edn. ISBN 9789241548151. https://www.who.int/water_sanitation _health/publications/2011/dwq_guidelines/en/. Accessed 5 Dec 2020 
40. Gomes, T. S., Vaccaro, L., Magnet, M., Izquierdo, F., Ollero, D., Martínez-Fernández, C., et al. (2020). Presence and interaction of free-living amoebae and amoeba-resisting bacteria in water from drinking water treatment plants. Science of the Total Environment, $719,137080$. 